Plant Tissue Cult. \& Biotech. 25(1): 87-97, 2015 (June)

$\overline{\text { PTC\&B }}$

\title{
Genetic Transformation of a Local Tomato (Solanum lycopersicum L.) Variety of Bangladesh
}

\author{
Pronabananda Das, Aneesa Ansari, Mohammad Nurul Islam* \\ and R. H. Sarker \\ Department of Botany, University of Dhaka, Dhaka-1000, Bangladesh
}

Key words: Genetic transformation, Agrobacterium, BARI Tomato-8

\begin{abstract}
An in vitro regeneration and Agrobacterium-mediated genetic transformation protocol was optimized for a local tomato variety, BARI Tomato-8 using cotyledonary leaf and hypocotyls explants. The explants were treated with various growth regulators in MS at different concentrations and combinations. Highest number of multiple shoot induction was observed from both the explants cultured in MS supplemented with $8.88 \mu \mathrm{M}$ BAP and 0.57 $\mu \mathrm{M}$ IAA. Half strength of MS supplemented with $1.14 \mu \mathrm{M}$ IAA was found to be the best for root induction from excised shoots. Agrobacterium mediated genetic transformation was carried using pBI121 plasmid harboring $\beta$-glucuronidase (GUS) reporter and nptII selectable marker genes. Transient GUS assay confirmed that both the explants pre-cultured for two days showed best transformation efficiency in bacterial suspension having optical density (OD) of 0.8 (at $600 \mathrm{~nm}$ ) for $15 \mathrm{~min}$ and co-cultivation period of 3 days. The shoots regenerated from transformed cotyledonary leaf explants survived at $200 \mathrm{mg} / \mathrm{l}$ kanamycin selection. The presence of expected amplicon corresponding to the GUS gene was confirmed by PCR. This protocol paves a way for developing disease resistant tomato variety using target gene/s.
\end{abstract}

\section{Introduction}

Tomato (Solanum lycopersicum L.) is one of the most important vegetable crops. The annual production is 163.96 million metric tons in 2013 throughout the world (faostat 2013). It was popular as it is eaten fresh and processed in multiple forms. In the developing countries, tomatoes are extensively cultivated. But, the plants are usually threatened with pests and insects which reduces the ultimate production. There are more than 200 pathogens namely, viruses, viriods, fungi,

*Author for correspondence: < mnurul@du.ac.bd>. 
bacteria, nematodes, parasite weeds, pests and insects, that infects tomato crop (Jones et al. 1997). The most devastating is the begamoviruses like tomato leaf curl virus and tomato yellow leaf curl virus which can decrease the yield by 100\% (Saikia et al. 1989). These viruses are transmitted by white flies and the only suitable way the farmers use to eradicate these flies is by using pesticides. Besides cost of these pesticides, farmers usually do not have adequate knowledge on the amount of the pesticides to be sprayed. More so, these chemicals tend to enter the food chain and cause environmental hazard.

Under these circumstances, establishment of a disease and insect resistant variety can be a better solution rather than use of the pesticides. Biotechnological technique has been used in many parts of the world (Ling et al. 1998 and Park et al. 2003). Agrobacterium-mediated genetic transformation is commonly used to transfer foreign gene(s) into dicotyledonous plants. Previously, in vitro regeneration and Agrobacterium-mediated genetic transformation protocol of BARI Tomato-3 and Pusa ruby variety was established in Bangladesh (Sarker et al. 2009). Several reports have been mentioned where attempts were being made to improve tomato transformation and regeneration (Horsch et al. 1985, McCormick et al. 1986, Fillatti et al. 1987, Tomassoli et al. 1999, Park et al. 2003, Cortina and Culianez-Mica 2004). Although a number of local and improved varieties of tomatoes are being cultivated in Bangladesh but all of them have been suffering from biotic and abiotic stresses. In order to, improve these varieties through the introduction of foreign gene/s conferring biotic and/or abiotic stress tolerance, establishment of a genotype independent regeneration and transformation protocol is essential. Therefore, the present study has been undertaken to establish an efficient and reproducible regeneration and Agrobacterium-mediated genetic transformation protocol for a farmer popular tomato variety in Bangladesh such as; BARI Tomato- 8 variety using selectable and screenable marker genes.

\section{Material and Method}

The seeds of the tomato variety BARI Tomato- 8 were collected from Bangladesh Agricultural Research Institute (BARI), Joydebpur, Gazipur. To generate explants, the seeds of BARI Tomato- 8 were treated in $0.1 \%(\mathrm{v} / \mathrm{v})$ mercuric chloride for 10 - 15 min with vigorous shaking, washed three times with autoclaved distilled water and inoculated onto the cotton bed for germination. These seeds were kept in the dark till the germination took place and finally transferred to 16-hourslight and 8 hours dark condition at $25 \pm 2{ }^{\circ} \mathrm{C}$ in growth room. The seedlings were used for explants preparation. The cotyledonary leaf and hypocotyls were first separated. The leaves were cut at tip and the base, 
removing the meristematic tissue, whereas the hypocotyls were segmented into approximately $0.5 \mathrm{~cm}$ in size. The explants were placed on a pre-culture media for 0,1 and 2 days before infection (Fig. $1 \mathrm{a}, \mathrm{b}$ ).

Table 1. Effects of various combinations of IAA, Kn, GA, NAA, BAP and 2,4-D in MS on regeneration and proliferation of multiple shoots from cotyledonary leaf and hypocotyls segments of BARI Tomato-8.

\begin{tabular}{|c|c|c|c|c|c|c|c|c|c|}
\hline \multicolumn{6}{|c|}{ Different combinations of hormones $(\mu \mathrm{M})$} & \multirow{2}{*}{$\begin{array}{c}\text { No. of } \\
\text { explants } \\
\text { inoculated }\end{array}$} & \multirow{2}{*}{$\begin{array}{l}\text { No. of } \\
\text { responsive } \\
\text { explants }\end{array}$} & \multirow[b]{2}{*}{$\begin{array}{c}\text { No. of } \\
\text { shoots } \\
\text { after } \\
60-70 \\
\text { days }\end{array}$} & \multirow{2}{*}{$\begin{array}{c}\text { Mean } \\
\text { no. of } \\
\text { shoots/ } \\
\text { explants }\end{array}$} \\
\hline IAA & Kn & $\mathrm{GA}_{3}$ & NAA & BAP & $2,4-\mathrm{D}$ & & & & \\
\hline \multicolumn{10}{|c|}{ Cotyledonary leaf } \\
\hline \multirow[t]{4}{*}{2.85} & 6.97 & 1.44 & & & & 50 & 27 & - & - \\
\hline & 9.3 & & 2.68 & & & 50 & 33 & - & - \\
\hline & & & 2.15 & 11.1 & & 50 & 37 & 14 & 0.37 \\
\hline & & & & 13.32 & 11.31 & 50 & 24 & - & - \\
\hline \multirow[t]{5}{*}{2.85} & & & & 11.1 & & 50 & 41 & 26 & 0.63 \\
\hline & & & & 8.88 & & 50 & 8 & 3 & 0.37 \\
\hline & 9.3 & & & & & 50 & 7 & 2 & 0.28 \\
\hline & & 1.44 & & 4.44 & & 50 & 19 & - & - \\
\hline & 4.65 & & & 8.88 & & 50 & 16 & 4 & 0.25 \\
\hline 1.14 & 4.65 & & & & & 50 & 26 & 11 & 0.42 \\
\hline 0.57 & & & & 4.44 & & 156 & 124 & 81 & 0.65 \\
\hline 0.57 & & & & 8.88 & & 875 & 759 & 1313 & 1.73 \\
\hline 0.57 & & & & 13.32 & & 186 & 140 & 76 & 0.54 \\
\hline 0.57 & & & & 22.2 & & 154 & 93 & 42 & 0.45 \\
\hline \multirow[t]{2}{*}{0.57} & & & & 26.64 & & 134 & 75 & 32 & 0.43 \\
\hline & \multicolumn{9}{|c|}{ Hypocotyls } \\
\hline \multirow[t]{4}{*}{2.85} & 6.97 & 1.44 & & & & 50 & 24 & - & - \\
\hline & 9.3 & & 2.68 & & & 50 & 28 & - & - \\
\hline & & & 2.15 & 11.1 & & 50 & 31 & 10 & 0.32 \\
\hline & & & & 13.32 & 11.31 & 50 & 18 & - & - \\
\hline \multirow[t]{5}{*}{2.85} & & & & 11.1 & & 50 & 35 & 15 & 0.43 \\
\hline & & & & 8.88 & & 50 & 8 & 1 & 0.23 \\
\hline & 9.3 & & & & & 50 & 8 & 2 & 0.25 \\
\hline & & 1.44 & & 4.44 & & 50 & 19 & - & - \\
\hline & 4.65 & & & 8.88 & & 50 & 16 & - & - \\
\hline 1.14 & 4.65 & & & & & 50 & 26 & 08 & 0.31 \\
\hline 0.57 & & & & 4.44 & & 156 & 104 & 62 & 0.60 \\
\hline 0.57 & & & & 8.88 & & 875 & 721 & 1145 & 1.59 \\
\hline 0.57 & & & & 13.32 & & 186 & 137 & 67 & 0.49 \\
\hline 0.57 & & & & 22.2 & & 154 & 82 & 30 & 0.37 \\
\hline 0.57 & & & & 26.64 & & 134 & 66 & 28 & 0.42 \\
\hline
\end{tabular}

MS in combination with different hormones were used for regeneration and transformation experiments. The $\mathrm{pH}$ of the medium was adjusted to 5.8. The medium was then autoclaved. Different combinations of hormone and 
supplements like IAA, $\mathrm{Kn}, \mathrm{GA}_{3}$, NAA, BAP and 2,4-D were added for multiple shoot regeneration (Table 1). In case of rooting, three types of media were used, i.e. MS containing $1.14 \mu \mathrm{M}$ IAA, half strength of MS containing $0.98 \mu \mathrm{M}$ IBA and half strength of MS containing $1.14 \mu \mathrm{M}$ IAA. The antibiotic kanamycin was used to select the transformed plants after infection with Agrobacterium tumefaciens carrying pBI121 plasmid containing nptII gene. Kanamycin was dissolved in distilled water and sterilized by filter. Once the autoclaved media was cooled, the antibiotic was added. The regenerated shoots were subcultured regularly at an interval of 12 - 15 days and the concentration of kanamycin was gradually increased (e.g. 100, 150, $200 \mathrm{mg} / \mathrm{l}$ ) in the regeneration medium.

Agrobacterium tumefaciens strain LBA4404 containing plasmid pBI121 of $14 \mathrm{~kb}$ (binary vector) was used for the transformation. This binary vector contains uidA gene (Jefferson et al. 1987) encoding GUS, driven by CaMV 35 S promoter and NOS terminator and nptII gene (Herrera-Estrella et al. 1983) encoding neomycin phosphotransferase II conferring kanamycin resistance within the right border (RB) and left border (LB) region of the T-DNA. The bacterium also contains plasmid pAL4404 which is a disarmed Ti plasmid $(132 \mathrm{~kb})$ containing the virulence genes.

The hypocotyls and the cotelydonary leaf explants were prepared and placed in a pre-culture media for 0,1 and 2 days before infection. Healthy explants that responded to pre-culture, as evident by swelling, were incubated in the bacterial suspension at different optical density with different timing of incubation period. The explants were then soaked on sterile tissue paper and co-cultured on the same pre-culture medium for 2 days at $28^{\circ} \mathrm{C}$. The explants were washed twice with autoclaved distilled water and finally washed with $300 \mathrm{mg} / \mathrm{l}$ of ticarcylin. For selection of transformed shoots, kanamycin containing regeneration medium was used. Cultures were subcultured regularly at an interval of 12 - 15 days and the concentration of kanamycin was gradually increased (e.g. 100, 150 and 200 $\mathrm{mg} / \mathrm{l})$ in regeneration medium. Plates were cultured under a $16 \mathrm{hrs}$ light $/ 8 \mathrm{hrs}$ dark cycle at $28^{\circ} \mathrm{C}$. The regenerated shoots were excised from the callus and transferred to a rooting medium.

Histochemical assay was performed to visualize GUS activity. The leaf tissues which survived the highest kanamycin concentration was selected and incubated in GUS histochemical buffer [ $50 \mathrm{mM}$ sodium phosphate, pH7.0; 50 mM EDTA, pH 8.0; $0.5 \mathrm{mM} \mathrm{K}{ }_{3} \mathrm{Fe}(\mathrm{CN})_{6} ; 0.5 \mathrm{mMK}_{4} \mathrm{Fe}(\mathrm{CN})_{6} ; 0.1 \%$ triton $\mathrm{X}-100 ; 1.0$ $\mathrm{mM}$ X-gluc (5-bromo-4-chloro-3-indolyl $\beta$-D-glucuronide)] at $37^{\circ} \mathrm{C}$ for up to 24 hrs. Chlorophyll in leaf tissues was subsequently removed by washing with $70 \%$ alcohol after every 3 days. For molecular analysis, the genomic DNA was isolated from the plantlets which survived under the highest selection pressure 
using modified CTAB method (Islam et al. 2011). Using the isolated DNA, PCR was performed with GUSA-769 (nucleotide sequence: TGG CTG TGA ACG CAC AGT TCA) and GUSA-10 (nucleotide sequence: CCT GTA GAA ACC CCA ACC CG) primers for molecular confirmation of the genetic transformation. The conditions for PCR was $95^{\circ} \mathrm{C}$ for $5 \mathrm{~min}, 94^{\circ} \mathrm{C}$ for $1 \mathrm{~min}, 56^{\circ} \mathrm{C}$ for $1 \mathrm{~min}, 72^{\circ} \mathrm{C}$ for 1 min and repeated for 30 cycles. The final extension was maintained $72^{\circ} \mathrm{C}$ for 10 minutes and paused at $4^{\circ} \mathrm{C}$. The amplified band was checked in the agarose gel.

\section{Results and Discussion}

For the development of transgenic plants through genetic transformation methods, the development of an efficient and reproducible in vitro regeneration protocol is a prerequisite (Gardner 1993). Thus, the development of a compatible regeneration protocol of BARI Tomato- 8 variety was tried first and then the transformation ability of Agrobacterium containing pBI121 construct conferring GUS reporter gene and nptII gene expression into the BARI Tomato- 8 variety was conducted.

The regeneration efficiency of seedlings of different ages ranged from 40 to $86.7 \%$ for BARI Tomato- 8 variety. The seedlings age showed highly significant effect on regeneration where a maximum of $86.7 \%$ and minimum of $40 \%$ values were recorded for 8 - 10 and 28 - 30 days, respectively. Thus 8 - 10 days seedlings were considered ideal for regeneration, as supported by Hamza and Chupeau 1993, Van Roekel et al. 1993, Ling et al. 1998. However, the regeneration percentage decreased distinctly with the increase in the age of seedling that is, more than 14 - 16 days.

Direct regeneration of tomato has been reported to vary with concentrations and combinations of hormones, light and incubation, genotype and explants used (Bhatia et al. 2004). Different concentrations and combinations of BAP, IAA, NAA, $\mathrm{GA}_{3}, 2,4-\mathrm{D}$ and $\mathrm{Kn}$ were used in MS to study their effects towards initiation and development of multiple shoots from the explants of BARI Tomato-8. Both the cotyledonary leaf and hypocotyls explants showed variable responses in all the hormonal supplements applied by regenerating multiple shoots. It was observed that the best hormonal supplements for shoot regeneration were $8.88 \mu \mathrm{M}$ BAP and $0.57 \mu \mathrm{M}$ IAA in MS where the percentage of responsive explants was $86.70 \%$ and mean no. of shoots per explants was 1.73\% (3 - 4 shoots from a single explants) (Table 1). Cotyledonary leaf explants showed good response towards multiple shoots regeneration on this medium (Figs. 1 c, d and e) as evident by different research reports (Mamidala and Nanna 2011, Gubis et al. 2003, Cortina and Culianez-Mica 2004 and Sarker et al. 2009). Similarly, hypocotyls explants also showed good response towards $8.88 \mu \mathrm{M}$ BAP and $0.57 \mu \mathrm{M}$ IAA where mean 
no. of shoots were $1.59 \%$. However, shoot regeneration capacities of the explants of BARI Tomato-8 on MS containing different concentrations of only BAP were very poor where the explants got enlarged and produced hard calluses, unlike observations reported by Sarker et al. 2009, where only BAP showed positive effect towards shoot regeneration.
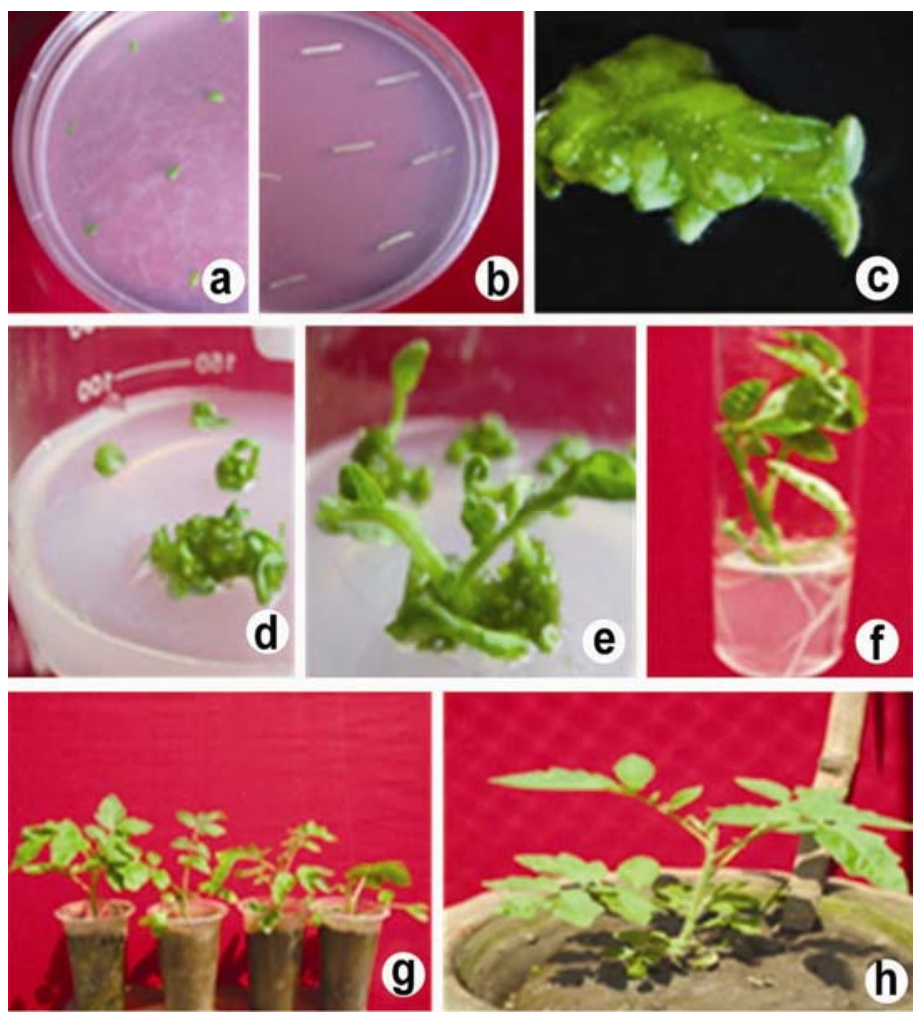

Fig. 1. Regeneration of BARI Tomato-8. $(a, b)$. Inoculation of cotyledonary leaf and hypocotyls explants of BARI Tomato-8 on MS medium supplemented with $8.88 \mu \mathrm{M}$ BAP $+0.57 \mu \mathrm{M}$ IAA for induction of multiple shoots, (c). Stereomicroscopic view of initiation of explants, (d). Initiation of multiple shoots from cotyledonary leaf explants of BARI Tomato- 8 on MS supplemented with 4.65 $\mu \mathrm{M} \mathrm{Kn}+1.14 \mu \mathrm{M}$ IAA, (e). Enlarged view of multiple shoots initiated from the cut surface of cotyledonary leaf explants of BARI Tomato- 8 on MS supplemented with $8.88 \mu \mathrm{M}$ BAP $+0.57 \mu \mathrm{M}$ IAA, (f). Induction of roots from excised regenerated shoots of BARI Tomato- 8 on half strength MS supplemented with $1.14 \mu \mathrm{M}$ IAA, (g). In vitro regenerated plantlets of BARI Tomato-8 transferred to small plastic pots containing soil, $(\mathrm{h})$. Regenerated plants of BARI Tomato- 8 acclimatized in large clay pots containing soil.

Developments of roots were tried on three different mediums namely, MS without any hormones, half strength of MS $+0.98 \mu \mathrm{M}$ IBA and $1 / 2 \mathrm{MS}+1.14 \mu \mathrm{M}$ IAA. Root formation was observed in all media. But the best rooting medium among them was half strength of MS with $1.14 \mu \mathrm{M}$ IAA. Profuse number of 
healthy roots about $92.30 \%$ formed in this medium (Fig. 1f) and the plants survived well in soil, when the regenerated shoots were transferred to half strength of MS medium supplemented with $1.14 \mu \mathrm{M}$ IAA as reported by Devi et al. (2008). Rooted plantlets of BARI Tomato- 8 were transferred to soil and successfully acclimatized (Fig $1 \mathrm{~g}$ and $\mathrm{h}$ ). These plants produced flower. Thus it can be concluded that this regeneration protocol is simple, reproducible.

Agrobacterium strain LBA4404 containing pBI121 construct containing GUS gene showed good interaction with hypocotyls and cotyledonary leaf explants. Here, the transformation procedure like optical density of bacterial suspension, incubation period and co-cultivation period were optimized., Out of four different optical density $(0.1,0.4,0.6$ and 0.8$)$, OD 600 of 0.8 was found best for the transformation of highest number of the explants after immersion in the bacteria containing medium for $15 \mathrm{~min}$. A co-cultivation period of $72 \mathrm{hrs}$ was suitable for the explants to survive from the Agrobacterium attack after incubation and help the proper transfer of T-DNA, as supported by Ling et al. 1998, Park et al. 2003 and Sarker et al. 2009. Highest transformation efficiency was observed with the $100 \%$ GUS expression of explants when the seedlings age was 8 - 10 days (Fig. 2 $a, b$ and c). The explants were also placed on a pre-culture of media for 2, 1 and 0 days before infection. It was found that the percentage of survival in case of the $48 \mathrm{hrs}$ pre-cultured cotelydonary leaf explants was significantly higher than the other pre-culture media. Whereas, survival percentage was comparatively low in case of hypocotyls explants (Table 2). Therefore, cotelydonary leaf explants was preferred over hypocotyls.
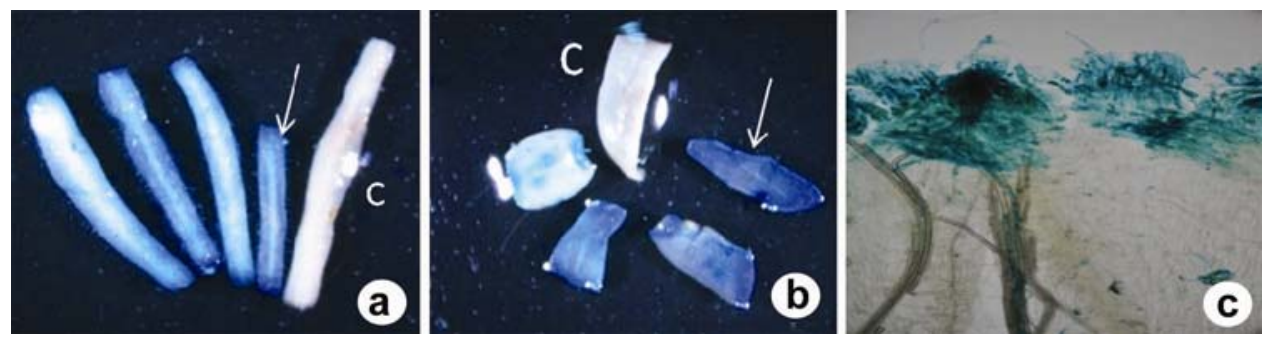

Fig. 2. Histochemical localization of GUS activity in the explants infected with Agrobacterium. (a) Hypocotyl segment explants (arrows) showing blue colour and Control explants (C) do not express blue color. (b) Cotelydonary leaf explants (arrows) showing blue colour and control explants (C) do not express blue color. (c) Magnified view of GUS positive hypocotyls showing characteristic blue color at the cut ends. $\times 40$.

The Agrobacterium strain used in this investigation harbored a binary plasmid pBI121 carrying nptII gene within its T-DNA and this gene confers kanamycin resistance to the transformed cells. Therefore, selection of the transformants was carried out using various concentrations of kanamycin. It was observed that co- 
cultivated explants, even in the presence of lower concentrations of kanamycin in regeneration media, failed to regenerate and consequently died. Therefore, selection pressure was not applied immediately after co-cultivation; instead, cocultivated explants were first allowed to stabilize in regeneration media without any selection pressure. After 15 - 20 days from the infected cotyledonary leaf explants very small shoots buds started regenerating and these regenerating explants were subjected to maintain under kanamycin selection pressure to select transgenic shoots. All control shoots died in the selection medium with $200 \mathrm{mg} / \mathrm{l}$ kanamycin. Kanamycin of $100 \mathrm{mg} / \mathrm{l}$ was applied in the initial selection medium and selection pressure was increased gradually in subsequent subcultures (Fig. 3 a, b). For selection, $50-100 \mathrm{mg} / \mathrm{l}$ kanamycin was reported to be suitable in obtaining transformed tomato shoots (Ling et al. 1998, Cortina and CulianezMica, 2004). The shoots those survived in presence of $150 \mathrm{mg} / \mathrm{l} \mathrm{kanamycin}$ were subjected to higher selection pressure with $200 \mathrm{mg} / \mathrm{l}$ kanamycin to obtain transformants (Fig. 3 c).
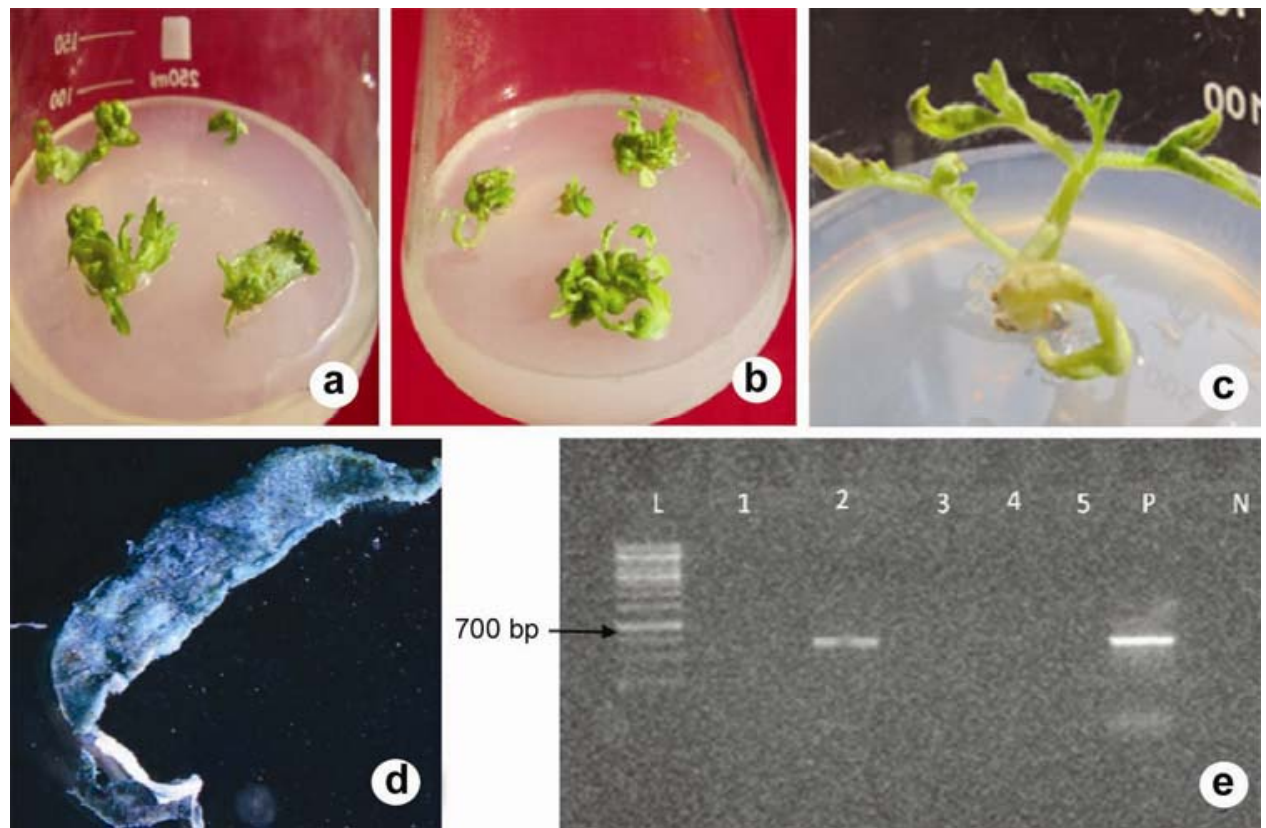

Fig. 3. Transgenic plant development. (a) Initiation of shoots from infected explants of BARI Tomato8 when the explants were transferred on regeneration medium containing $100 \mathrm{mg} / \mathrm{l}$ kanamycin. (b) Development of multiple shoots from Agrobacterium infected explants of BARI Tomato- 8 when the explants were transferred on regeneration medium containing 150 mg/l kanamycin. (c) Transformed shoots of BARI Tomato- 8 surviving in the medium containing $200 \mathrm{mg} / \mathrm{l} \mathrm{kanamycin.} \mathrm{(d)} \mathrm{Leaf} \mathrm{of} \mathrm{transgenic} \mathrm{plant} \mathrm{showing} \mathrm{blue} \mathrm{colour} \mathrm{when} \mathrm{treated} \mathrm{with}$ histochemical GUS assay (e) PCR band $\mathrm{L}=1 \mathrm{kbp}$ ladder, $1-5=$ Leaf samples, $\mathrm{P}=$ Positive control, $\mathrm{N}=$ Negative control. 
The transgenic nature of the transformed plants was confirmed by two ways: histochemical GUS assay and PCR. Histochemical GUS assay was carried out once before infection and second time after the selection of the transgenic plants that survived in the $200 \mathrm{mg} / \mathrm{l}$ kanamycin. The explants, i.e. cotyledonary leaf and hypocotyls showed blue zone coloration under stereoscope microscope. This reveals that both the explants have the capacity of getting infected by Agrobacterium (Fig. 2 a, b, and c). The leaf of the transgenic plant that survived under highest kanamycin selection derived from the cotelydonary leaf explants showed blue color on a number of shoots when subjected to GUS assay (Fig. 3d). Although, not all the survived plants showed GUS positive, this might be due to the capacity of reversing of the plant into non-transgenic, such phenomenon has been reported by Ying et al. 1992 and Ottaviani et al. 1993. This shows that the GUS expression does not directly correlate with kanamycin resistance. The lack of GUS expression in kanamycin resistant plant may be due to the change or loss of GUS gene resulting from methylation of the gene or rearrangement of the coding sequence (Ottaviani et al. 1993).

Table 2. Influence of optical density 0.8 (measured at $600 \mathrm{~nm}$ ) of Agrobacterium strain LBA4404/pBI121 suspension on transformation of three different types pre-cultured cotyledonary leaf and hypocotyl explants.

\begin{tabular}{lcccc}
\hline $\begin{array}{l}\text { Types of } \\
\text { Explants }\end{array}$ & $\begin{array}{c}\text { Pre-culture } \\
\text { Time before } \\
\text { infection } \\
\text { (days) }\end{array}$ & $\begin{array}{c}\text { No. of infected } \\
\text { explants assayed for } \\
\text { GUS expression }\end{array}$ & $\begin{array}{c}\text { No. of GUS } \\
\text { positive } \\
\text { explants }\end{array}$ & $\begin{array}{c}\text { Percentage of } \\
\text { GUS positive } \\
\text { explants }\end{array}$ \\
\hline Cotyledonary & 0 & 40 & 31 & 77.50 \\
leaf & 1 & 40 & 35 & 87.50 \\
& 2 & 40 & 38 & 95.00 \\
Hypocotyl & 0 & 40 & 24 & 60.00 \\
& 1 & 40 & 27 & 67.50 \\
\hline
\end{tabular}

The leaves of the transgenic plants which showed GUS positive color were further confirmed by using PCR. The amplification of GUS gene was done using gene specific primers. After 30 cycles of amplification the PCR products were visualized through agarose gel electrophoresis. The PCR products showed a band at $700 \mathrm{bp}$ similar to the positive control (Fig. 3 e).

It can be concluded that the regeneration response of the cotelydonary leaf explants was better than hypocotyls and subsequently, transgenic plants obtained from cotyledonary leaf explants following the regeneration protocol. Therefore, this protocol endeavors a new and efficient way for obtaining 
transgenic plants which can be used to transfer useful candidate genes conferring disease, insect and pest resistance in the BARI Tomato- 8 variety of Bangladesh.

\section{Acknowledgement}

The authors are thankful to the International Centre for Genetic Engineering and Biotechnology (ICGEB), Trieste, Italy for providing financial support to the underlying investigation through CRP-ICGEB Grants No. CRP/BGD11-01.

\section{References}

Bhatia P, Ashwath N, Senaratana T and Midmore DJ (2004) Tissue culture studies in tomato (Lycopersicon esculentum). Plant Cell Tiss. Organ Cult. 78: 1-21.

Cortina C and Culianez-Macia FA (2004) Tomato transformation and transgenic plant production. Plant Cell, Tissue and Organ Cult. 76: 269-275.

Devi MK, Banu AR, Gnanaprabhal GR, Pradeep BV and Palaniswamy M (2008) Purification, characterization of alkaline protease enzyme from native isolate Aspergillus niger and its compatibility with commercial detergents. Indian J. Sci. Technol. 1: 7

Fillati JJ, Kiser J, Rose R and Comai L (1987) Efficient transfer of a glyphosate tolerance gene into tomato using binary Agrobacterium tumefaciens vector. Bio-technology 5: 726730.

Gardner RC (1993) Gene transfer into tropical and subtropical crops. Scientia Hort. 55: 6582.

Gubis J, Lajchova Z, Farago J and Jurekova Z (2003) Effect of genotype and explant type on shoot regeneration in tomato (Lycopersicon esculentum Mill.) in vitro. Czech j. Genet. Plant Breed. 39: 9-14.

Hamza S and Chupeau Y (1993) Re-evaluation of conditions for plant regeneration and Agrobacterium-mediated transformation from tomato (Lycopersicon esculentum). J. Exp. Bot. 44: 1837-1845.

Herrera-estrella L, A Depicker, MV Montagu and J Schell (1983) Expression of chimaeric genes transferred into plant cells using a Ti-plasmid-derived vector. Nature 303: 209 213.

Horsch RB, Frye JE, Hoffman NF, Eichoholtz D, Rogers SG and Fraley RT (1985) A simple and general method for transferring genes into plants. Science 227: 1229-1231. http://faostat3.fao.org

Islam MN and Mukherjee SK (2011) Construction of MYMIV based gene silencing vector and its use. ISBN: 978-3-8443-8820-6. LAP-LAMBERT Academic Publishing GmbH \& Co. KG. Dudweiler Landstr. 99, 66123 Saarbrücken, Germany.

Jefferson RA, Klass M, Wolf N, Hirsh D. (1987) Expression of chimeric genes in Caenorhabditis elegans.J Mol Biol. 193(1): 41-46.

Jones JB, Stall RE and Zitter TA (1997) Compendium of Tomato Diseases, The APS press. Minnesota. USA. pp. 4-13. 
Ling HQ, Kriseleit D and Ganal MW (1998) Effect of ticarcillin/potassium clavulanate on callus growth and shoot regeneration in Agrobacterium-mediated transformation of tomato (Lycopersicon esculentum Mill.). Plant Cell Rep. 17: 843-847.

Mamidala P and Nanna RS 2011.Effect of genotype, explant source and medium on in vitro regeneration of tomato. International Journal of Genetics and Molecular Biology 3(3): 45-50.

McCormick S, Niedermeyer J, Fry J, ABarnason, Horsch R and Fraley R (1986) Leaf disc transformation of cultivated tomato (L. esculentum) using Agrobacterium tumefaciens. Plant Cell Rep. 5: 81-84.

Ottaviani MP, Smits T and Hanish CH (1993) Differential methylation and expression of the $\beta$-glucuronidase and neomycin phosphotransferase genes in transgenic plants of potato cv. Bintje. Plant Science 88: 73-81.

Park SH, JL Morris, Park JE, Hirscho KD and Smith RHM (2003) Efficient and genotype independent Agrobacterium mediated tomato transformation. J. Pl. Physio. 160(10): 1253-1257.

Saikia AK and Muniyappa V (1989) Epidemiology and control of tomato leaf curl virus in Southern India. Trop. Agric. (Trinidad) 66: 350-354.

Sarker RH, Islam K and Hoque MI (2009) In vitro regeneration and Agrobacteriummediated genetic transformation of tomato (Lycopersicon esculentum Mill.). Plant Tiss. Cult. \& Biotech. 19(1): 101-111.

Tomassoli L, Ilardi V, Barba M and Kaniewski W (1999) Resistance of transgenic tomato to cucumber mosaic cucumovirus under field conditions. Mol. Breed. 5: 121-130.

Van Roekel JSC, Damm B, Melchers LS and Hoekema A (1993) Factors influencing transformation frequency of tomato. Plant Cell Rep. 12: 644-647.

Ying M, Dyer WEB and Gergman IW (1992) Agrobacterium tumefaciens-mediated transformation of safflower (Cathamus tinctroius L.). Plant Cell Rep. 11(11): 581-585. 